\title{
Trends in adverse weather patterns and large wildland fires in Aragón (NE Spain) from 1978 to 2010
}

\author{
A. Cardil ${ }^{1}$, D. M. Molina ${ }^{1}$, J. Ramirez ${ }^{2}$, and C. Vega-García ${ }^{1}$ \\ ${ }^{1}$ School of Agrifood and Forestry Science and Engineering, University of Lleida, Avenida Rovira Roure 191, \\ 25198 Lleida, Spain \\ ${ }^{2}$ Department of Agricultural Sciences and Technology, University of Leon, Avenida de Portugal 41, 24071 León, Spain
}

Correspondence to: A. Cardil (adriancardil@gmail.com)

Received: 1 December 2012 - Published in Nat. Hazards Earth Syst. Sci. Discuss.: Revised: 23 April 2013 - Accepted: 27 April 2013 - Published: 31 May 2013

\begin{abstract}
This work analyzes the effects of high temperature days on large wildland fires during 1978-2010 in Aragón (NE Spain). A high temperature day was established when air temperature was higher than $20^{\circ} \mathrm{C}$ at $850 \mathrm{hPa}$. Temperature at $850 \mathrm{hPa}$ was chosen because it properly characterizes the low troposphere state, and some of the problems that affect surface reanalysis do not occur. High temperature days were analyzed from April to October in the study period, and the number of these extreme days increased significantly. This temporal trend implied more frequent adverse weather conditions in later years that could facilitate extreme fire behavior. The effects of those high temperatures days in large wildland fire patterns have been increasingly important in the last years of the series.
\end{abstract}

\section{Introduction}

Mediterranean countries like Spain have numerous wildland fires each year (Pereira et al., 2011). Fire has always been part of the traditional Mediterranean agrarian land management, occasionally developing into unwanted fires (Millán et al., 1998). However, over the past $30 \mathrm{yr}$ wildland fires have became more extreme, with fire behavior more and more often exceeding firefighting capabilities (Miralles et al., 2010; Molina et al., 2010), and fire agencies experience difficulties in suppressing extreme-behavior fires while providing safety for both firefighters and citizens, as reviewed in Werth et al. (2011). The social and physical/biological environment has changed dramatically, and wildfires constitute nowadays one of the problems that consistently obtain more attention from the media in summer. Agricultural abandonment is the main cause of an increased fuel load (Millán et al., 1998), but wildland fuel homogeneity and continuity are also major facilitators of both a fast fire propagation and a higher fire line intensity (Molina et al., 2010; Vega-García and Chuvieco, 2006). In addition, climate and weather are two of the main factors influencing fire regime (Trouet et al., 2009), and climate change could have an important impact on ecosystems due to increases in area burned and fire intensity/severity (Flannigan et al., 2000). Regato (2008) showed that climate change could provide an increase in the intensity and frequency of summer heat waves (short periods with very hot days, very low air humidity and frequently with strong winds) that increase the probability of large wildland fire (LWF)

Typically, just a few LWFs cause the majority of the damage (Alvarado et al., 1998; Ganteaume and Jappiot, 2012) because they account for a very high percentage of the total burned area (Stocks et al., 2003), and their severity is normally higher. In these LWF events fire behavior is often extreme, making suppression difficult. Therefore, LWFs affect our ecosystems, human safety and properties to the utmost (Alvarado et al., 1998) and also demand vast resources to suppress them.

It is essential to know what factors influence LWFs. We have focused on days with high temperatures (HTDs) to assess their potential impact on the development of LWFs. Previous works indicate that HTDs might provide more extreme weather conditions (Montserrat, 1998), which have an important role in forest fire behavior (Crimmins, 2006). Hot days decrease fuel moisture and increase the ignition 


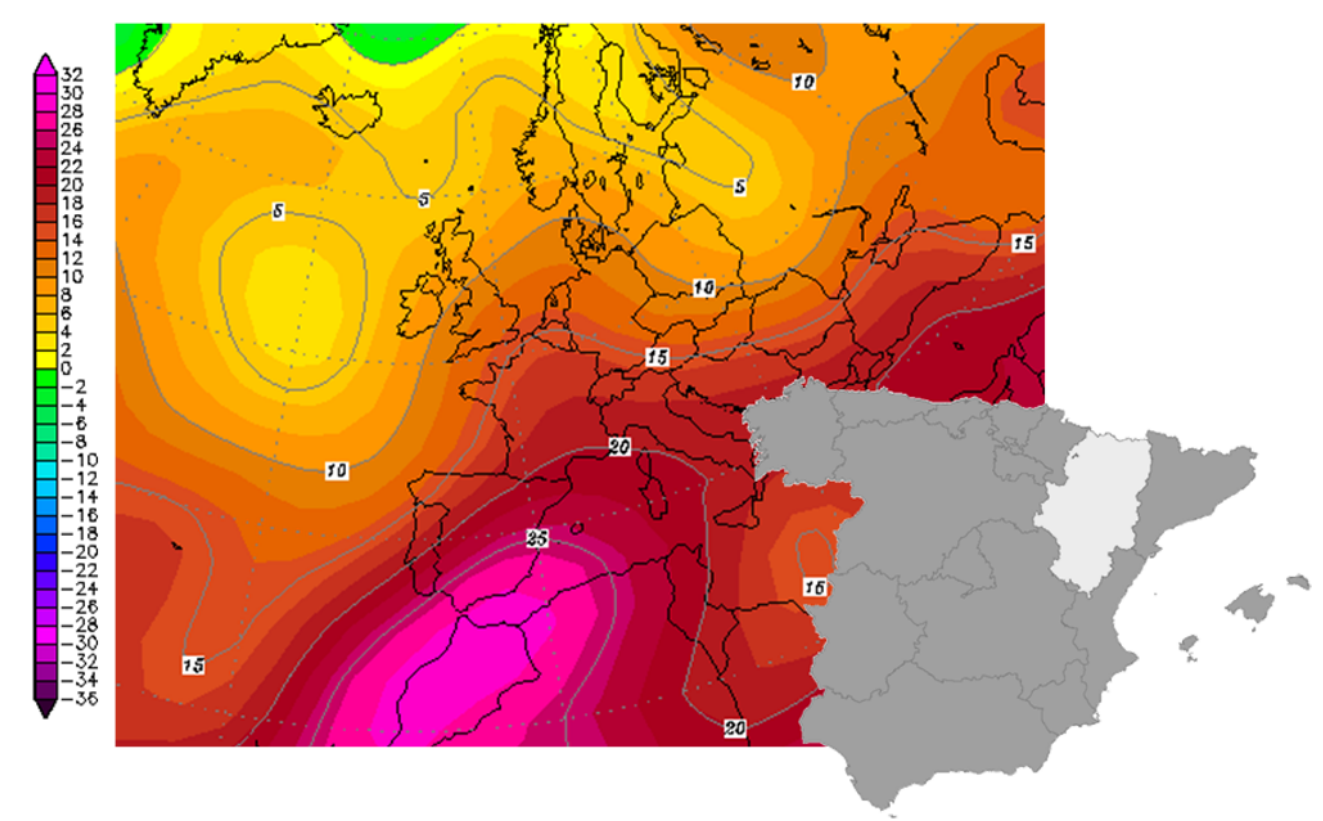

Fig. 1. Geographic location of Aragón and air temperature at $850 \mathrm{hPa}$ (legend in ${ }^{\circ} \mathrm{C}$ ) for 2 July 1994. Source: www.wetterzentrale.de.

probability and, as a result of that influence, other aspects such as longer flame length, most likely involving crown fire activity and spotting activity (long distance ignition by convection processes). Therefore, HTD has the potential to increase the probability of having a LWF. In a similar way, Mills (2005) indicates that unusually strong temperature gradients at $850 \mathrm{hPa}$ (which usually stands for a level around $1500 \mathrm{~m}$ up in the atmosphere) may have the potential to identify unusually severe fire weather events. It would be extremely profitable to be able to discriminate between the simply "bad" and the "disastrous" fire days with some reasonable lead time (i.e., 24 or $48 \mathrm{~h}$ ).

The five largest LWFs on record in Aragón did develop under HTDs. In addition, those HTDs were extreme. The largest fire in Aragón affected 16832 ha in Villarluengo (Teruel) on 2 July 1994, and air temperature at $850 \mathrm{hPa}$ and at 00:00 UTC in the Aragón region was higher than $22.5^{\circ} \mathrm{C}$ (Fig. 1), during the day of the fire and also on the two previous days. In this case, the synoptic weather pattern that caused the HTD was a hot air mass inlet (south advection from the Sahara desert).

The exploration for underlying causes and visible patterns of LWFs is instrumental to plan best strategies for our suppression resources and to foresee extreme fire behavior. In this study, we have analyzed HTDs in the Spanish region of Aragón and their relationship to the LWF official records both in terms of amount and cumulative area burned and number of LWFs in HTDs versus non-HTDs.

\section{Methods}

\subsection{Study area}

Aragón is the fourth largest region in Spain $\left(47719 \mathrm{~km}^{2}\right)$ and is located in the northeastern part of the country (Fig. 1). The region has 1.34 million inhabitants, comprises the provinces of Huesca, Teruel and Zaragoza, and it is politically divided in 33 counties. Aragón has a high altitudinal gradient that generates several ecosystems in the region. There is a major river (Ebro) bordered by two mountain chains: the Pyrenees (maximum altitude $3404 \mathrm{~m}$, Aneto) and the Iberian System (maximum altitude $2314 \mathrm{~m}$, Moncayo). The climate in Aragón can be generally regarded as a Mediterranean climate with continental nuances, but the irregular topography influences it and generates local climate variability. The environment varies from the high mountains of the north-central Pyrenees, with perpetual ice (glaciers) to the steppe or semidesert areas, such as Monegros, and intense continental climate in other areas. The mean annual temperature ranges from $22.5^{\circ} \mathrm{C}$ in the Ebro valley to $5^{\circ} \mathrm{C}$ in the highest areas of Pyrenees, and the average annual rainfalls also ranges from $1800 \mathrm{~mm}$ in the highest mountains to $300 \mathrm{~mm}$ in the valley (AEMET, 2012). The vegetation is conditioned by relief and climate. In upland forests there are several tree species (pine, fir, beech, oak), shrubs and meadows. In the Ebro valley, oak and juniper trees are the most common and there are degraded areas covered by shrubs and grasslands. Aragón has high ecological value with several protected wilderness areas. 


\subsection{High temperature days in Aragón}

In order to characterize the high temperature days, reanalysis data from the National Centers for Environmental Prediction (NCEP) were used (Kalnay et al., 1996). We analyzed daily air temperature maps ( $850 \mathrm{hPa}$ at 00:00 UTC) to assess whether there was a HTD condition in the territory. Air temperature at $850 \mathrm{hPa}$ is the air temperature at an altitude in the atmosphere where pressure is $850 \mathrm{hPa}$ (around $1500 \mathrm{~m}$ up in the atmosphere). The $850 \mathrm{hPa}$ air temperature daily maps were available at Wetterzentrale (2013). We established that there was a HTD when air temperature at $850 \mathrm{hPa}$ was equal to or higher than $20^{\circ} \mathrm{C}$ in at least two-thirds of the Aragón region. We chose the temperature at $850 \mathrm{hPa}$ because it is generally used to analyze past fire weather and fire weather forecasts (Millán et al., 1998; Garcia-Ortega et al., 2011; Trigo et al., 2006). It provides a regional coverage as well because it is sufficiently close to the surface to be representative of the low troposphere state, and it avoids some of the problems that affect near-surface reanalysis variables (Trigo et al., 2005; Ogi et al., 2005). An air temperature at $850 \mathrm{hPa}$ equal to or higher than $20^{\circ} \mathrm{C}$ is associated with heat waves, and this condition provides high temperatures in surface and low relative humidity in the territory (Montserrat, 1998).

Weather conditions were characterized every day from 1978 to 2010 in the fire season from April to October (included). We analyzed the number of HTDs and the duration and frequency of the high temperature (HT) phenomena as a proxy for potential fire behavior. We defined "HT periods" as the number of uninterrupted times that a HTD occurred.

\subsection{Large wildland fires}

Large wildland fires (LWFs) are defined in this work as those over 100 ha threshold (Moreno et al., 2011; De Zea Bermudez et al., 2009). In order to understand the interactions between HTD and LWF in the study period (19782010) in Aragón, we processed the historical fire data records from Spain's EGIF database (General Statistics on Wildland Fires; see www.magrama.gob.es, accessed last time on 30 October 2012), which includes the wildland fire reports sent to the Ministry of the Environment by the firefighting and forest management services of all the Spanish regions. This database has an entry from each fire, regardless of size, and contains the same fields of information for each fire. The first years of the database (1968-1977) were not used in this study because the area burned on private properties were usually underreported in those years because the Forest Service mandate was to suppress only on state-owned or state-controlled forest but not privately owned lands (Antonio Muñoz, Forest Service, personal communication). Many fires smaller than 100 ha in the database most likely burned a larger area (maybe more than $100 \mathrm{ha}$ ) because foresters did not account for the area of burnt private land. Therefore, there are missing $100 \mathrm{ha}+$ fires prior to 1977 . We have analyzed trends in the number of LWFs, LWF area burned and average LWF size under both HTDs and non-HTDs.

In the study period, there were 193 wildland fires in Aragón larger than 100 ha that burned 132000 ha approximately. All of them affected forest and agricultural areas, roads and people. For instance, the four forest fires that occurred on 22 July 2009 in Teruel (the Aliaga, Alloza, Cedrillas and Corbalán fires) burned about 10000 ha in total.

\subsection{Statistical analysis}

The relationship between HTDs and LWFs was assessed in the period up to two days immediately before LWF occurrence date, and analyzed according to the following four HTD classes:

- Class A: LWFs that start on a HTD (day 0), HTD (day 1) and HTD (day 2), therefore, LWFs under a very strong HT period.

- Class B: LWFs that start on a HTD (day 0), HTD (day 1) and non-HTD (day 2), therefore, LWFs under a strong HT period.

- Class C: LWFs that start on a HTD (day 0), non-HTD (day 1) and HTD or non-HTD (day 2), therefore, LWFs under a weak HT period.

- Class D: LWFs that start on a non-HTD (day 0), HTD or non-HTD (day 1) and HTD or non-HTD (day 2). Therefore, they were fires with minor influence of HT conditions.

Only two days before all LWFs have been used in this analysis. Several days before each LWF were analyzed (5 days), but they did not influence the results, and previous days (day 3, day 4 and day 5) did not supply more information than HT classes used (above). We evaluated the influence of HTD on LWF on three consecutive days by using an ANOVA analysis and group comparison with the Fisher method with a $95 \%$ confidence interval.

We also quantified how many LWFs were conditioned by HTDs (only on the day that the fires started), and we summarized statistics in the studied period. We established the number of LWFs, burned area swept by them, the average size and percentage of LWFs under HTDs and non-HTDs.

We determined if there were significant changes (decrease, increase, no difference) in the studied variables (number of LWFs, area burned by LWFs and number of HTDs) from 1978 to 2010 with a linear regression analysis on annual raw data. The annual variability in fire occurrences is high, both in terms of large fire frequencies and their burned areas (Stocks et al., 2003). This variability is caused by diverse environmental factors, such as human influence (Mollicone et al., 2006) and climate (Gillett et al., 2004). For this reason, we added the evolution in time of the variables with the 


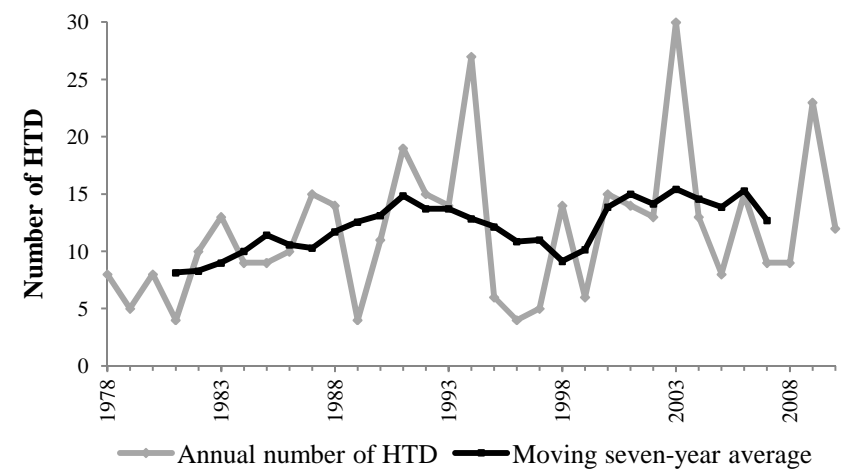

Fig. 2. Annual number of high temperature days (HTDs) (light grey line) in Aragón from 1978 to 2010 and moving seven-year average (black line) from 1981 to 2007.

moving average method in order to obtain a better display in the figures. This smoothing technique was applied to mitigate the effect due to year to year random variation. This practice, when properly applied, reveals more clearly the underlying trend (Legendre and Legendre, 1998). "The method calculates successive arithmetic averages over $2 \mathrm{~m}+1$ contiguous data as one moves along the data series" (Legendre and Legendre, 1998). In this study, we used simple moving average with seven-year periods $(m=3)$.

\section{Results}

\subsection{HTD trends}

The annual number of HTDs increased in the study period significantly ( $p$ value $=0.020$ ). It rose from 8 HTDs in 1981 to 15 in 2006 in terms of seven-year average values, as shown in Fig. 2. The number of HT periods also increased ( $p$ value $=0.022$ ). Therefore, in recent years, we have more periods influenced by HTD phenomena. However, the average duration of HT periods did not change in the study period with an average duration of 2.2 days.

The majority of HTD events took place in mid-summer (July and August) with more than $80 \%$ of the total. June has $11.5 \%$ of days and September $5.8 \%$. In April, there were no HTDs; in October, there was only one HTD in the studied period. June had a significant increase in the number of HTDs from 0.7 days in 1981 to 2.7 in 2006 in terms of seven-year average. In July, August and September, no significant trends were observed.

\subsection{Large wildland fires}

A decrease in the total annual number of LWFs was observed in Aragón during the study period ( $p$ value $=0.003$ ) It diminished from 12 LWFs in 1981 to 3 LWFs in 2007 in terms of seven-year average values. The annual number of LWFs under non-HTDs also decreased significantly
Table 1. Trends in annual number of large wildland fires (LWFs), annual area burned, and annual number of high temperature days (HTDs) in Aragón from 1978 to 2010.

\begin{tabular}{llll}
\hline Variable & Total & HTD & Non-HTD \\
\hline Number of LWFs & $-(0.003)$ & n.s $(0.411)$ & $-(<0.001)$ \\
Area burned & n.s $(0.968)$ & n.s $(0.590)$ & $-(0.014)$ \\
HTD & $+(<0.020)$ & & \\
\hline
\end{tabular}

+ significantly increased; - significantly decreased at $P<0.05$; n.s. not significant Values in parentheses are the $P$ statistic.

( $p$ value $<0.001$ ). It diminished from 8 LWFs in 1981 to 2 LWFs in 2007 in terms of seven-year average values. By contrast, the annual number of LWFs under HTDs did not decrease in the study period. Neither total annual area burned nor annual area burned under HTDs changed in the study period. Nevertheless, a significant decrease was found in the annual area burned under non-HTDs. It decreased from 2204 ha in 1981 to 780 ha in 2007 in terms of seven-year average values.

HTDs also influence the average LWF size, and HTD classes explain the variable average size of the LWFs ( $p=$ 0.003). Table 1 lists the number of LWFs, area burned and average size of LWFs in each HTD class (1978-2010). The HTD class comparison analysis shows that there was a significant difference between both A and B classes and D class. Average LWF size in D class was a third of those of both A and $\mathrm{B}$ classes (Table 2). No significant difference between class $\mathrm{C}$ and other classes can be established.

We split the study period in two intervals (1978-1993 and 1994-2010) because in 1994 there were LWFs with an extreme behavior under very strong HTD conditions. The average LWF size increased significantly between 19781993 and $1994-2010$ periods ( 424 ha vs. 1275 ha) ( $p$ value $=$ 0.001). Additionally, the average LWF size under HTDs is significantly larger in the 1994-2010 period (1923 ha) than in the 1978-1993 period (590 ha) ( $p$ value $=0.024$ ). However, the average LWF size under non-HTDs did not change between two periods (389 ha). In the first interval (1978-1993), the majority of LWFs were under D class with 5.59 LWFs and 1987 ha burned per year. In the second interval (19942010), the results changed significantly and the annual number of LWFs was 1.69 and the annual area burned was 858 ha (Table 2). By contrast, in HTD classes (A, B and C) neither annual number of LWFs nor annual area burned decreased between the two time intervals, and the annual area burned was higher in 1994-2010 interval in both A and B classes while the percentage of LWF number under HTD versus total LWF number was $54.2 \%$ and the area burned was $81.7 \%$. Additionally, in the 1994-2010 period, most of the surface (76\%) was burned by LWFs under A and B classes (in which HTD conditions were strong or very strong). The HTD influence in LWF increased in Aragón in the study period as shown in Fig. 4 with two ratios that indicate that most LWFs 
Table 2. Number of large wildland fires (LWFs), area burned and average size in high temperature (HT) classes in Aragón from 1978 to 2010.

\begin{tabular}{rrrrrrrr}
\hline Classes & $\begin{array}{r}\text { Number } \\
\text { of fires }^{\mathrm{a}}\end{array}$ & $\begin{array}{r}\text { Area } \\
\text { burned }^{\mathrm{a}} \\
\text { (ha) }\end{array}$ & $\begin{array}{r}\text { Average } \\
\text { size }^{\mathrm{b}} \\
(\text { ha) }\end{array}$ & $\begin{array}{r}\text { Annual number } \\
\text { of fires }^{\mathrm{c}} \\
1978-1993\end{array}$ & $\begin{array}{r}\text { Annual number } \\
\text { of fires }^{\mathrm{c}} \\
1994-2010\end{array}$ & $\begin{array}{r}\text { Annual area } \\
\text { burned }^{\mathrm{c}}\left(\text { ha }^{2}\right. \\
1978-1993\end{array}$ & $\begin{array}{r}\text { Annual area } \\
\text { burned }^{\mathrm{c}}\left(\mathrm{ha}^{2}\right) \\
1994-2010\end{array}$ \\
\hline $\mathrm{A}$ & 25 & 35311 & $1412 \pm 699$ & $0.82 \pm 0.29$ & $0.69 \pm 0.25$ & $462 \pm 122$ & $1716 \pm 1087$ \\
$\mathrm{~B}$ & 26 & 34388 & $1323 \pm 419$ & $0.53 \pm 0.22$ & $1.06 \pm 0.24$ & $291 \pm 182$ & $1840 \pm 919$ \\
$\mathrm{C}$ & 20 & 14913 & $746 \pm 423$ & $0.94 \pm 0.47$ & $0.25 \pm 0.06$ & $604 \pm 390$ & $291 \pm 66$ \\
$\mathrm{D}$ & 122 & 47502 & $389 \pm 49$ & $5.59 \pm 1.21$ & $1.69 \pm 0.39$ & $1987 \pm 437$ & $858 \pm 251$ \\
\hline Total & 193 & 132114 & $685 \pm 115$ & $7.88 \pm 1.67$ & $3.69 \pm 1.04$ & $3344 \pm 756$ & $4704 \pm 2156$ \\
\hline
\end{tabular}

${ }^{\mathrm{a}}$ Absolute values in the study period. ${ }^{\mathrm{b}}$ Mean and standard error $(\sigma / \sqrt{ } n)$ values over the period. ${ }^{\mathrm{c}}$ Annual mean and standard error $(\sigma / \sqrt{ } n)$ values.

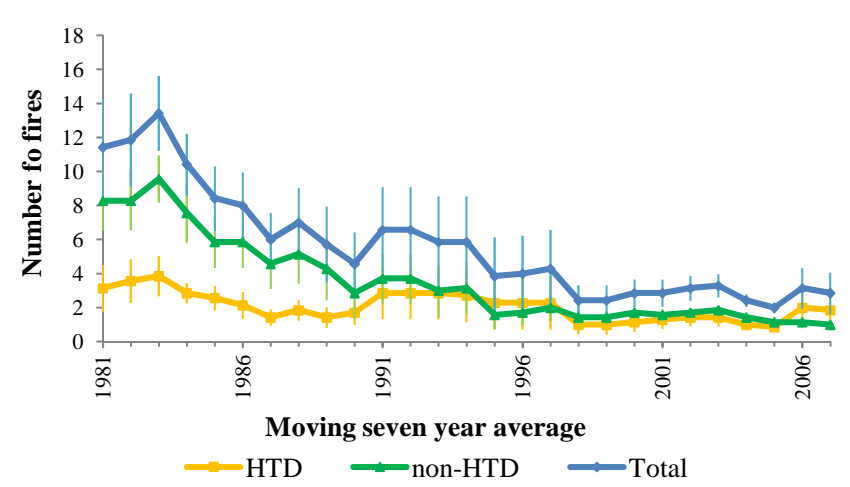

Fig. 3. Number of large wildland fires in Aragón under high temperature days (HTDs), non-high-temperature days (non-HTDs) and total number of large wildland fires (LWFs) in Aragón from 1978 to 2010. Moving seven-year average from 1981 to 2007 . Vertical lines are the annual standard error values.

took place nowadays under HTDs and that was not the case in the 1980s and 1990s. The ratio of LWF number under HTDs versus total number of LWFs increased in the study period (Fig. 3) from 0.28 in 1981 to 0.65 in 2007. The ratio of LWF area burned under HTDs versus total area burned also increased from 0.45 in 1981 to 0.82 in 2007 (Fig. 4). The values of these ratios are in seven-year average.

In terms of area burned by LWFs, the worst years of the series were 1994 and 2009 with 32600 ha and 21925 ha respectively. More than $90 \%$ of the total burned area (in these two years) was burned under HTD conditions. These years also have a very high annual number of HTDs: 27 HTDs in 1994 and 23 in 2009. Moreover, the largest fires in Aragón did spread in this HTD conditions.

\section{Discussion}

While it is recognized that the major elements for fire weather forecasts are low humidity, high temperatures, and strong winds near the ground, meteorological indexes planned to evaluate temporal and spatial dissimilarities in

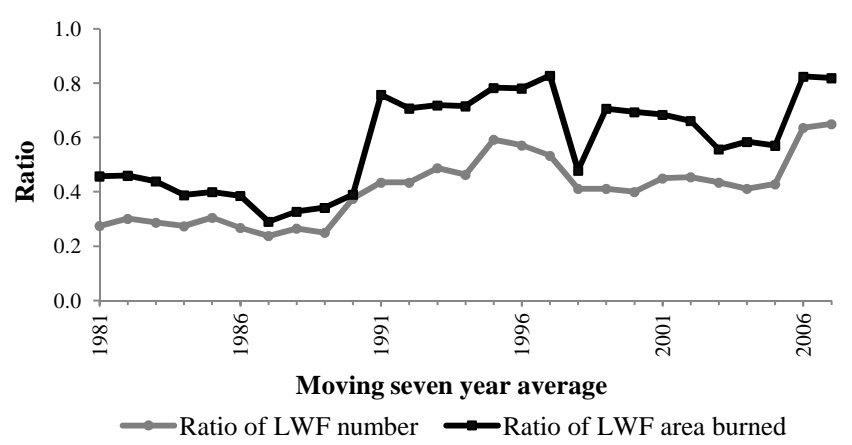

Fig. 4. Ratio of LWF area burned under HTDs versus total area burned and ratio of LWF number under HTDs versus total number of LWFs in Aragón from 1978 to 2010. Moving seven-year average from 1981 to 2007.

those elements are not frequently used or available by all fire weather forecast agencies (Charney and Keyser, 2010; Crimmins, 2006). For that very reason, we highlight the importance of discerning between HTD and non-HTD defined by $850 \mathrm{hPa}$ synoptic conditions in planning pre-suppression efforts to stand up to large fires.

An increase was found in the number of HTDs in the study period, and this agrees with Rodriguez-Puebla et al. (2010). The main source of this increase might be related to the weather regime that brings hot dry air masses from the north of Africa (Rodriguez-Puebla et al., 2010). Different authors suggested that this increase might be linked to an increase of temperature in northeastern Spain due to climate change (Moreno, 2005; Giannakopoulos et al., 2009; Kettunen et al., 2007). Giannakopoulos et al. (2009) suggested that the number of hot days $\left(T_{\max }>30^{\circ} \mathrm{C}\right)$ and heat wave days $\left(T_{\max }>35^{\circ} \mathrm{C}\right)$ will increase in Spain. Giannakopoulos et al. (2009) estimate that there will be 1 to 3 additional hot weeks per year. The mean annual temperature will increase, with greatest warm-up rate in southern Europe (Moreno, 2005; Castro et al., 2005; Kettunen et al., 2007). Van Wagner and Pickett (1985) remarked that the fire weather index will increase in summer (i.e., increasing fire risk). Therefore, if 
HTDs become more frequent and these conditions are able to decrease air humidity and fuel moisture and increase the fire behavior potential, we may be facing larger wildland fires in the future, and very likely extreme-behavior fires beyond suppression capacity (Molina et al., 2010). We also found that in the last years of the series there were more days under HT conditions in June. This may be translated as an increase in fire season length.

Both the total annual number of LWFs and the annual number of LWFs under non-HTDs decreased in Aragón from 1978 to 2010. Nevertheless, the annual number of LWFs under HTDs did not decrease in the same period. The total annual area burned did not decrease due to the area burned by LWFs under HTDs. However, a decrease in the annual area burned under non-HTD conditions was observed. Additionally the percentage of both LWF occurrence and area swept by LWFs under HTDs also increased. Three main reasons could explain this. First, the number of HTDs was greater at the end of the time series, and it is more likely to have a LWF under HTDs. Second, in the last years, fire suppression resources have improved in technology and training, and, therefore, LWFs under non-HTDs are suppressed more efficiently because the fuel moisture content is higher. Fires under HTDs have lower fuel moisture content and can propagate faster and with higher fire line intensity. Third, HTDs are more prone to have simultaneous fire events (LWFs or smaller fires) that split suppression resources.

The average LWF size in all fires increased in the study period (from 424 ha in 1978-1993 period to 1275 ha in 1994 2010 period), and this could be related to the major percentage of LWFs under HTDs in the last years of the series because the average LWF size in both A and B classes was larger than LWFs in non-HT conditions or weak HT conditions (class $\mathrm{C}$ and $\mathrm{D}$ ). The fact that average LWF size increased under HTDs, when resources were better organized and trained than ever, reinforces the importance of these HT conditions and their influence on both total and average size per LWF in the period 1994-2010. The largest historical fires in Aragón happened under extreme HTDs in both 1994 and 2009. This supports the statement that HTDs provide more extreme conditions for fire propagation and more difficulties to suppress those fires. This has also occurred in other countries (Trigo et al., 2006; Mills, 2005), such as Russia (2010), Portugal (2003), Australia (different years), Greece (2007) and USA $(2011,2012)$.

\section{Conclusions}

There are significant effects of HTD conditions in the number of LWFs, total LWF area burned, and average LWF size in Aragón. As a result, if in the future the number of HTD conditions increases, fire suppression will be compromised. This is likely to happen because our study shows that the incidence of both the number of HTD and HT periods has increased significantly in the study period.

It would be extremely profitable to be able to discriminate between the simply "bad" and the "very bad" or "terrible" fire days with some reasonable lead time (i.e., 24 or $48 \mathrm{~h}$ ). We suggest that this classification regarding HTDs and nonHTDs (at $850 \mathrm{hPa}$ ) be used for that discrimination.

In terms of burned area, a decrease was observed only in annual area burned under non-HTDs. Total area burn is stable. This may indicate greater fire damage as more area is burned under HTDs.

Most HTDs are in July and August (82\% of total). However, June is becoming more active in HTDs lately. This indicates an earlier, longer fire season.

Acknowledgements. We are thankful to the University of Lleida and Pau Costa Foundation for supporting this study through a partial grant to fund Cardil's PhD studies. We also thank Joaquim García-Codina, Miguel Lazaro and Luis Besold for help in the classification of HTDs and other detailed checking in the official wildland fire data base, and finally to Marta Fajo-Pascual and Antonio Muñoz for help in the statistical analysis and the EGIF Database.

Edited by: B. D. Malamud

Reviewed by: M. G. Pereira and two anonymous referees

\section{References}

AEMET: Iberian climate atlas. Air temperature and precipitation (1971-2000), State meteorological Agency of Spain and Department of Meteorology and Climatology of the Institute of Meteorology, Portugal, 80 pp., 2012.

Alvarado, E., Sandberg, D. V., and Pickford, S. G.: Modeling large forest fires as extreme events, Northwest Sci., 72, 66-75, 1998.

Castro, M., Martín-Vide, J., and Alonso, S.: El clima de España: pasado presente y escenarios de clima para el siglo XXI, Impactos del cambio climático en España, Spanish Ministry of the Environment ed., CSIC, 1-65, 2005.

Charney, J. J. and Keyser, D.: Mesoscale model simulation of the meteorological conditions during the 2 June 2002 Double Trouble State Park wildfire, Int. J. Wildland Fire, 19, 427-448, 2010.

Crimmins, M. A.: Synoptic climatology of extreme fire-weather conditions across the southwest United States, Int. J. Climatol., 26, 1001-1016, 2006.

De Zea Bermudez, P., Mendes, J., Pereira, J. M. C., Turkman, K. F., and Vasconcelos, M. J. P.: Spatial and temporal extremes of wildfire sizes in Portugal (1984-2004), Int. J. Wildland Fire, 18, 983-991, 2009.

Flannigan, M. D., Stocks, B. J., and Wotton, B. M.: Climate change and forest fires. Sci. Total Environ., 262, 221-229, 2000.

Ganteaume, A. and Jappiot, M.: What causes large fires in Southern France, Forest. Ecol. Manag., 294, 76-85, doi:10.1016/j.foreco.2012.06.055, 2012.

García-Herrera, R., Díaz, J., Trigo, R. M., and Hernández, E.: Extreme summer temperatures in Iberia: health impacts and 
associated synoptic conditions, Ann. Geophys., 23, 239-251, doi:10.5194/angeo-23-239-2005, 2005.

García-Ortega, E., Trobajo, M. T., López, L., and Sánchez, J. L.: Synoptic patterns associated with wildfires caused by lightning in Castile and Leon, Spain, Nat. Hazards Earth Syst. Sci., 11, 851-863, doi:10.5194/nhess-11-851-2011, 2011.

Giannakopoulos, C., Le Sager, P., Bindi, M., Moriondo, M., Kostopoulou, E., and Goodess, C. M.: Climatic changes and associated impacts in the Mediterranean resulting from a $2^{\circ} \mathrm{C}$ global warming, Global Planet Change, 68, 209-224, 2009.

Gillett, N. P., Weaver, A. J., Zwiers, F. W., and Flannigan, M. D.: Detecting the effect of climate change on Canadian forest fires, Geophys. Res. Lett., 31, L18211, doi:10.1029/2004GL020876, 2004.

Kalnay, E., Kanamitsu, M., Kistler, R., Collins W., Deaven, D., Gandin, L., Iredell, M., Saha, S., White, G., Woollen, J., Zhu, Y., Chelliah, M., Ebisuzaki, W., Higgins, W., Janowiak, J., Mo, K. J., Ropelewski, C., Wang, J., Leetmaa, A., Reynolds, R., Jenne, R., and Joseph, D.: The NCEP/NCAR 40-year reanalysis project, Bull. Am. Meteor. Soc., 77, 437-471, 1996.

Kettunen, M., Terry, A., Tucker, G., and Jones, A.: Guidance on the maintenance of landscape features of major importance for wild flora and fauna - Guidance on the implementation of Article 3 of the Birds Directive (79/409/EEC) and Article 10 of the Habitats Directive (92/43/EEC), Institute for European Environmental Policy (IEEP) ed., $114 \&$ anexxes pp., 2007.

Legendre, P. and Legendre, L.: Numerical ecology, 2nd Edn., Elsevier, 854 pp., 1998.

Millán, M. M., Estrela, M. J., and Badenas, C.: Meteorological processes relevant to forest fire dynamics on the Spanish mediterranean coast, J. Appl. Meteorol., 37, 83-100, 1998.

Mills, G. A.: A re-examination of the synoptic and mesoscale meteorology of Ash Wednesday 1983, Austr. Meteorol. Mag., 54, 35-55, 2005.

Miralles, M., Kraus, D., Molina, D., Loureiro, C., Delogu, G., Ribet, N., and Vilalta, O.: Improving suppression fire capacity. Research Report - European Forest Institute (EFI), 203-215, 2010.

Molina, D. M., Castellnou, M., Garcia-Marco, D., and Salgueiro, A.: Improving fire management success through fire behaviour specialists, Research Report - European Forest Institute (EFI), 105-119, 2010.

Mollicone, D., Eva, H. D., and Achard, F.: Ecology: Human role in Russian wild fires, Nature, 440, 436-437, 2006.

Montserrat, D.: Situaciones sinópticas relacionadas con el inicio de grandes incendios forestales en Cataluña, NIMBUS, 1-2, 93112,1998

Montserrat, D., Martin-Vide, J., and Llasat-Botija, C.: Climatología sinóptica aplicada a la prevención de incendios forestales en Cataluña, Montes, 109, 9-15, 2012.

Moreno, J. M.: Impactos sobre los riesgos naturales, Riesgo de incendios forestales, Evaluación preliminar de los impactos en España por Efecto del Cambio climático, Spanish Ministry of the Environment, 581-615, 2005.
Moreno, J. M., Viedma, O., Zavala, G., and Luna, B.: Landscape variables influencing forest fires in central Spain, Int. J. Wildland Fire, 20, 678-689, 2011.

Ogi, M., Yamazaki, K., and Tachibana, Y.: The summer northern annular mode and abnormal summer weather in 2003, Geophys. Res. Lett., 32, L04706, doi:10.1029/2004GL021528, 2005.

Pereira, M. G., Malamud, B. D., Trigo, R. M., and Alves, P. I.: The history and characteristics of the 1980-2005 Portuguese rural fire database, Nat. Hazards Earth Syst. Sci., 11, 3343-3358, doi:10.5194/nhess-11-3343-2011, 2011.

Regato, P.: Adapting to global change: Mediterranean forests, Malaga, Spain: IUCN Centre for Mediterranean Cooperation, 254 pp., 2008.

Rodriguez-Puebla C., Encinas, A. H., García-Casado, L. A., and Nieto, S.: Trends in warm days and cold nights over the Iberian Peninsula: relationships to large-scale variables, Climatic Change, 100, 667-684, 2010.

Stocks, B. J., Mason, J. A., Todd, J. B., Bosch, E. M., Wotton, B. M., Amiro, B. D., Flanningan, M. D., Hirsch, K. G., Logan, K. A., Martell, D. L., and Skinner, W. R.: Large forest fires in Canada, 1959-1997, J. Geophys. Res. Atmos., 108, 5-12, 2003.

Trigo, R. M., García-Herrera, R., Díaz, J., Trigo, I. F., and Valente, M. A.: How exceptional was the early August 2003 heatwave in France?, Geophys. Res. Lett., 32, L10701, doi:10.1029/2005GL022410, 2005.

Trigo, R. M., Pereira, J. M., Mota, B., Calado, T., Dacamara, C., and Santo, F.: Atmospheric conditions associated with the exceptional fire season of 2003 in Portugal, Int. J. Climatol., 26, 1741-1757, 2006.

Trouet, V., Taylor, A. H., Carleton, A. M., and Skinner, C. N.: Interannual variations in fire weather, fire extent, and synoptic-scale circulation patterns in northern California and Oregon, Theor. Appl. Climatol., 95, 349-360, 2009.

Van Wagner, C. E. and Pickett, T. L.: Equations and FORTRAN program for the Canadian Forest Fire Weather Index System, Canadian Forestry Service, Forestry Technical Report 33, 1985.

Vega-García, C. and Chuvieco, E.: Applying local measures of spatial heterogeneity to Landsat-TM images for predicting wildfire occurrence in Mediterranean landscapes, Landscape Ecol., 21, 595-605, 2006.

Werth, P. A., Potter, B. E., Clements, C. B., Finney, M., Goodrick, S. L., Alexander, M. E., Cruz, M. G., Forthofer, J. A., and McAllister, S. S.: Synthesis of knowledge of extreme fire behavior: volume I for fire managers. Gen. Tech. Rep. PNW-GTR-854, Portland, OR: USDA, Forest Service, Pacific Northwest Research Station, 2011.

Wetterzentrale: Archiv der NOAA-CR20 und NCEP Reanalysis, available at: http://www.wetterzentrale.de, last access: 5 March 2013. 